\title{
Practice of Autonomous Learning Mode in the Course of "Web Design and Production"
}

Yao Li ${ }^{*}$

Hangzhou Normal University, Hangzhou 311121, Zhejiang, China. E-mail: 1356020009@qq.com

Abstract: The autonomous learning model is one of the dominant learning models in the era of "Internet + education". It is sought after by teachers and students in universities. The learning style of college students is shifting from passive to active learning. And the traditional teaching model in the course of "Web Design and Production" is easy to cause the problems of poor learning enthusiasm of students and low teaching effect. According to the characteristics of the course, this article explores how autonomous learning can stimulate students' learning motivation and improve the learning effect of this course. It also designs a corresponding autonomous learning instructional model to mobilize students' learning enthusiasm, and to improve the instructional efficiency of the course.

Keywords: Web Design and Production; Autonomous Learning Model

\section{Introduction}

"Web Design and Production" is the core course of educational technology (pedagogic). It has a high degree of comprehensiveness and practicality. The teaching contents cover not only the basic knowledge of website construction and maintenance, web page layout, web element positioning, hyperlink technology, CSS style application, web dynamic effect creation, website testing and publishing, but also web design, Dreamweaver and other web production software. The most important is to combine them together to cultivate students' comprehensive ability in Web art design and static website development, which is a new challenge to improve students' computer operation skills. At present, teachers of the course mainly adopt the traditional lecture method, mainly by teachers and students passively learning. Moreover, the class time is limited, while the course has a certain depth. So, students will feel that the course is very boring in the learning process, the internal learning motivation is very low, and it is difficult for them to grasp the key points. In order to improve students' enthusiasm for learning "Webpage Design and Production”, improve the teaching effect of the course, the teaching method should be reformed.

The idea of autonomy is an important product of the Enlightenment in the 18th century, meaning independence and autonomy. Enlightenment thinkers believe that learning autonomy is a group of learning-related categories, composed of learning self-awareness, self-discipline and self-action. True autonomous learning is hardly the result of teachers' deliberate or unintentional efforts ${ }^{[1]}$. It only occurs when learners are engaged in self-shaping work. However, self-directed learning and other guided learning are a pair of categories, which are mainly of complementarity, and rarely of mutual substitution. Therefore, formal education is very important for cultivating independent learning ability ${ }^{[2]}$. The autonomous learning mentioned in this article is a learning model. In

\footnotetext{
Copyright (C) 2020 Yao Li

doi: 10.18282/jnt.v2i4.1375

This is an open-access article distributed under the terms of the Creative Commons Attribution Non-Commercial License

(http://creativecommons.org/licenses/by-nc/4.0/), which permits unrestricted non-commercial use, distribution, and reproduction in any medium, provided the original work is properly cited.
} 
this learning model, under the macro control of the overall teaching goal and the guidance of the teacher, students formulate and complete specific learning goals according to their own conditions and needs ${ }^{[3]}$. The cultivation of students' autonomous learning ability is in line with the needs of social development and the trend of future development.

\section{Problems existing in the course of "Web Design and Production"}

Currently, the "Web Design and Production" course mainly uses the translated version of the "HTML5 and CSS3 Basic Course” (8th edition) edited by Castro and Hislop in the United States ${ }^{[4]}$. The theoretical course corresponding to the book is only 32 hours, but the content to be taught includes 21 chapters of the textbook, with a total of more than 400 pages. In the learning process, teachers also need to add some knowledge that is not covered by textbooks but is necessary and related to the latest development of the website. In the previous teaching model, the teacher's speech was dominant, apart from answering questions, there was almost no interaction between teachers and students. Teachers can only understand the learning situation through the students' homework. However, after the students have completed each chapter's homework, it has been 2 to 4 weeks since the initial learning. It is difficult for the teacher to understand the students learning situation in time.

\subsection{Insufficient motivation for learning}

The school of the author takes "deep foundation + superb skills" as the direction of cultivating educational technology professionals, but it has encountered some problems in practice. One of them is an extensive curriculum and an imperfect curriculum system. Students not only need to learn knowledge in related education fields, but also need to enhance their ability to use technology, making it difficult for most students to strike a balance in the learning process and easily causing preference.

The course of "Web Design and Production" mainly adopts the instruction method combining theory and practice. From a textbook perspective, there are more than 400 pages of teaching content to be taught in a semester, and dozens of pages of new knowledge should be taught within 90 minutes. This is unrealistic. This also leads to theoretical lessons occupying practical classroom time. It is difficult for students to review after class, and they cannot absorb, adapt and develop their cognition in time. In order to complete the teaching task, the teacher has been talking until the end, and there is no interaction with the students. This leads to problems that marginalize students. Chris Frankson once pointed out, "Lectures that do not pay attention to student learning are like throwing ideas into students' subconscious mailboxes; you only know when to post, but you don't know when and how to receive these letters" ${ }^{\text {,[5] }}$. Only when students practice, teachers realize that students still face many problems in learning, but there is not enough time to remedy them, they have to continue to impart new knowledge and form a vicious circle. It is unable to mobilize the enthusiasm of students to learn actively, and students are not interested in learning. However, an efficient and successful classroom should become one that not only promotes students' active and meaningful learning, but also can give full play to the teacher's guidance advantages.

\subsection{Theory content being separated from practice}

Teachers mostly use lecture method to teach, that is first explaining the professional knowledge points and software technology operation demonstration, and then letting the students imitate the operate based on memory or classroom notes. The teaching content is monotonous and boring. Learning mechanically, students have low learning enthusiasm, and a weak grasp of professional knowledge. Because the mastery of basic and professional theories is not solid, students cannot respond quickly when they encounter problems. The disconnection between theoretical content and practical content prevents students from effectively combining declarative knowledge with procedural knowledge, theoretical knowledge and practical knowledge. Most students who seriously imitate operations are still at the level of mechanical imitation and do not understand knowledge. Students did not absorb knowledge, let alone transfer the knowledge they learned to actual jobs.

\subsection{Low ability to solve problems autono- mously}

Students are in a passive state for a long time in the learning process. Therefore, most students cannot think 
independently when they find problems in the learning process, and they cannot independently explore solutions to problems. When they encounter some simple problems, many students do not know how to set about solving the problem, and don't even know how to use search engines to find information effectively.

\subsection{Lack of confidence in coping with chal- lenges}

According to the quality of students' assignments and the entire learning process, when students learn more basic knowledge, they will show higher enthusiasm in the classroom and have a higher degree of overall mastery. However, when they later learned the layout of web pages to construct websites and other content, about half of the students turned their attention to designing web pages using software such as Adobe Photoshop. Part of the reason for this phenomenon is that students in this major have already taken a course in "graphic design" before, and web design is easier than web production. The fundamental reason is that most students are afraid of facing challenges and difficulties, and their motivation for avoiding failure is strong. This led to the problem of exquisite page design in the assignments submitted by students later, but poor technical application.

\section{Autonomous learning mode of "Web Design and Production" course}

\subsection{Autonomous learning teaching mode and “Web Design and Production”}

After experiencing elementary, junior high and high school education, college students have reduced their learning of formula concepts and test-taking knowledge, increased their diversified knowledge about thinking development, and the integration of knowledge between multidisciplinary fields. According to the analysis of the questionnaire, most students said that self-learning under the guidance of the teacher is their favorite and applicable learning method. This model can not only promote the development of intellectual potential, but also cultivate students' independent exploration learning methods and habits, and improve their learning ability ${ }^{[6]}$.

The autonomous learning teaching model is a teaching method based on constructivist learning theory and humanistic learning theory. This is a teaching model that reflects subject position of students and guiding function of teachers. In this article, it refers to the discovery of the learner's the zone of proximal development during the teaching process. With multiple specific small projects as the main line, students can actively use learning resources to carry out independent exploration and interactive collaborative learning, and be guided to produce a learning practice activity while completing each learning project. The autonomous learning teaching model has changed the traditional teaching concepts and the role of teachers. It focuses on the cultivation of students' autonomous learning ability and emphasizes cooperation and communication. It can give full play to the enthusiasm and creativity of learners in the learning process and ensure the dominance of learners ${ }^{[7]}$.

\subsection{Teaching process based on autonomous learning mode}

\subsubsection{Curriculum design}

The entire learning process of the "Web Design and Production” course is conducted in groups. In the first half of the course, students freely form groups of 2-3 people to carry out the learning process. In the second half of the course, the learning process is conducted in units of 4 to 5 people. The overall course arrangement is shown in Figure 1. 


\begin{tabular}{|c|c|c|c|c|c|}
\hline \multicolumn{6}{|c|}{ Web Design and Production } \\
\hline $\begin{array}{l}\overline{\bar{\sigma}} \\
\stackrel{\Xi}{\Xi}\end{array}$ & $\begin{array}{l}\text { Content: Learn the basics of HTML } \\
\text { language, build a website, use as } \\
\text { many tags as possible to write web } \\
\text { pages and run them in the browser, } \\
\text { and each group needs at least } 10 \\
\text { pages. The tools used are } \\
\text { Dreamweaver, Notepad, etc. } \\
\text { Achievement: Each team successfully } \\
\text { runs more than } 10 \text { pages written in } \\
\text { HTML on the browser and explain } \\
\text { the tags used. } \\
\text { Purpose: In order to improve } \\
\text { students' practical ability, enable } \\
\text { studengs to learn HTML elements as } \\
\text { much as possible, and promote } \\
\text { students to have a solid basic } \\
\text { knowledge. }\end{array}$ & $\underset{N}{\stackrel{\vec{\sigma}}{\Xi}}$ & $\begin{array}{l}\text { Content: Master the use of Div+CSS to lay } \\
\text { out web pages, and each group will make no } \\
\text { less than } 10 \text { pages of beautiful websites with } \\
\text { CSS layout. The more attributes used, the } \\
\text { better. The web pages are processed in a } \\
\text { responsive manner. The use of tools is not } \\
\text { limited. } \\
\text { Achievement: Each group successfully runs a } \\
\text { webpage with Div+CSS layout of more than } \\
5 \text { pages on the browser and explains the } \\
\text { knowledge used. } \\
\text { Purpose: To improve students' practical } \\
\text { ability, and enable students to experience that } \\
\text { CSS can greatly improve the efficiency of } \\
\text { web development, and understand the } \\
\text { development principles of large-scale website } \\
\text { production. }\end{array}$ & $\begin{array}{l}\bar{\sigma} \\
\stackrel{\vec{\sigma}}{\Xi} \\
\omega\end{array}$ & $\begin{array}{l}\text { Content: Design webpages through Photoshop } \\
\text { or XD; use HTML language, CSS layout, } \\
\text { Bootstrap framework or other types of } \\
\text { frameworks to develop a web front end; } \\
\text { combine with simple dynamic website } \\
\text { technology to design a relatively complete } \\
\text { website. The subject of the project is the official } \\
\text { website of the school. } \\
\text { Achievement: Each group ( } 4-5 \text { people) } \\
\text { successfully runs a well-designed and relatively } \\
\text { complete website on the browser, and reports on } \\
\text { the project process in detail. } \\
\text { Purpose: To promote students to master the } \\
\text { content of this course and improve their ability } \\
\text { to comprehensively apply knowledge. }\end{array}$ \\
\hline & 12 periods & \multicolumn{2}{|r|}{20 periods } & & 32 periods \\
\hline
\end{tabular}

Figure 1. Course schedule

\subsubsection{Type of class}

According to the different tasks arranged in the class time, it can be roughly divided into two types: ordinary class time and project report class time. In ordinary classes, each class (a total of 4 class hours) includes pre-class attendance, course self-study status check, lectures, student self-study, teacher's personal guidance and assignment of self-study tasks after class ${ }^{\left[{ }^{[8]}\right.}$. Project report class time is arranged after each project is completed. In the 4 class hours, the main content is that each group reports on the completion of the project, summarizes the knowledge used, students in the non-reporting group ask questions and score, and finally the teacher makes comments. The main content of the lecture is the key and difficult content of the new class carefully selected by the teacher. This course uses "UMU platform” as an auxiliary teaching method. "UMU platform" is a classroom interactive teaching platform based on the mobile Internet environment, which can realize instant interaction between teachers and students, resource push and homework tasks. The platform adds more interactivity to classroom teaching, such as attendance, roll call, question display and scoring. The classroom flowchart is shown in Figure 2 and Figure 3.

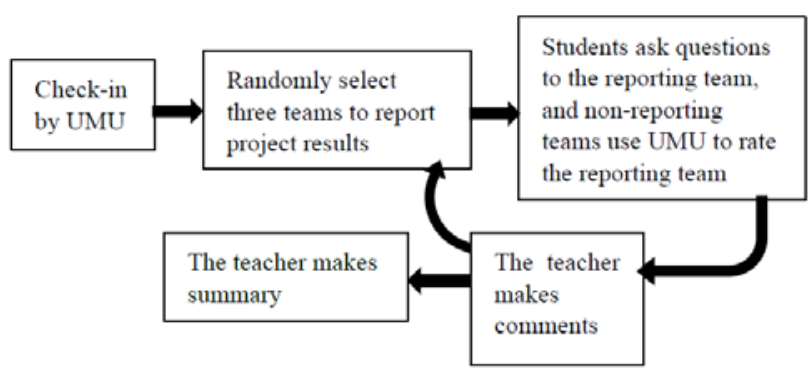

Figure 2. Flow chart of ordinary lessons

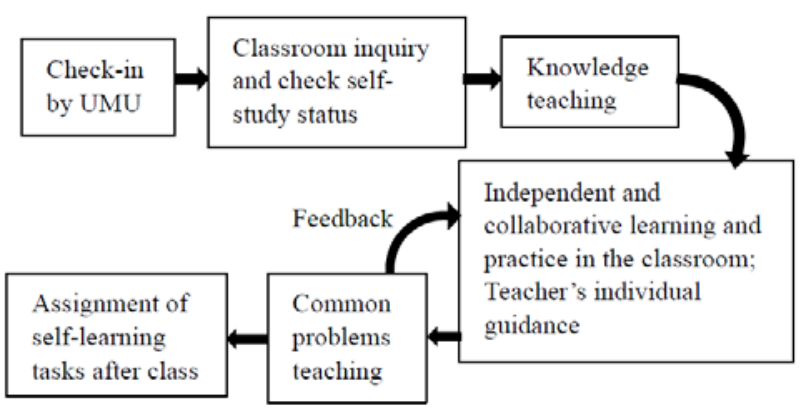

Figure 3. Flow chart of project report lessons

Before class, teachers need to prepare the learning resources needed for class in advance, including some tutorials related to the learning of website in each lesson, and provide them to students in time to encourage students to study independently. Teachers should provide timely feedback to students who answer questions (such as extra points). When learning new knowledge, the teacher's lectures are coordinated with the students' autonomous learning, focusing on the students' hands-on attempts. The teacher encourages students to cooperate with their peers in autonomous learning, ask the teacher, and solve problems through student-student discussions 
and teacher-student discussions. At the end of the class, the teacher needs to clearly describe the content of each chapter and the focus of students' self-study after class. A good self-study effect can encourage students to have active and profound interactions with teachers in the classroom.

Students' self-study content before each class is to complete the browsing and reading of the self-study content assigned by the teacher. Since "Web Design and Production” is a highly operable course, corresponding operations are also required in the actual reading process $^{[9]}$. Students need to mark the problems encountered during self-study before class. The teacher basically arranges the content of autonomous learning for students in chapters. In each formal class, the teacher will ask the students questions to fully understand the self-study situation. Students' autonomous learning before class must be combined with the teacher's clear assignment of tasks and classroom problems, otherwise blind assignment of tasks will only make students feel bored and difficult to persist.

The process of students' autonomous learning in the classroom requires teachers to play a "dominant” position. Before the start of classroom autonomous learning, teachers should give detailed and appropriate lectures on the key and difficult content of this lesson, find the students' "zones of proximal development", and find targeted independent learning resources for students, and provide students with space for independent learning on the basis of ensuring that they understand and master key content. After students enter the stage of autonomous learning in the classroom, they can solve problems through self-exploration and group communication. However, it cannot blindly emphasize the initiative of students and ignore the guidance of teachers in their professional fields ${ }^{[10]}$. The main task of teachers at this stage is to correct students' mistakes, provide individualized guidance to solve their problems encountered in their self-learning before class and the problems encountered in the process of self-learning in class, and give a unified explanation of some common problems. After the teacher's targeted instruction, students can not only solve the content that they have difficulty understanding in the learning process, but also discover the problems they have ignored or did not think about in the learning process, which can promote students to have a certain depth of thinking in learning.

In the project report course, each group will present the completed results and explain the knowledge used. Each student in each group must take turns explaining the division of labor in detail. This gives every student the opportunity to express themselves fully. Students in other groups will ask questions about their results, and according to the evaluation criteria given by the teacher, each group will give a score to the reporting group. The teacher will integrate the report situation, the group's mutual evaluation, the small group work and the teacher's opinion to evaluate the individual's final grade. Of course, after each group of reports, the teacher should give timely feedback, including the overall quality of the project, continuous improvement, tips on production skills, difficulties encountered in the production process and solutions.

\section{Teaching evaluation and re- thinking}

In the teaching of this semester "Webpage Design and Production", students are able to build static websites proficiently. They can build complete websites by themselves based on website planning books, using tools such as Photoshop or XD + Dreamweaver, and have a good understanding of HTML and CSS language. About $85 \%$ of the students in the major can use the knowledge learned in HTML language, CSS language and Bootstrap framework to develop the front end of the website. Nearly $60 \%$ of the students can use simple dynamic website technology and connect the front and back ends of the website. Even $10 \%$ of the students' final project not only have a beautiful design and a reasonable layout, but also have a good structure ${ }^{[11]}$.

In the middle stage of the course, especially after Chapter 7, some students have a low ability to accept challenges when accepting new knowledge and maintain a tendency to avoid failure. Therefore, they choose the task to design websites in the process of teamwork. Because students of this major have taken graphic design courses before, website design is relatively easy. There are also some students who tend to give up when learning more complex knowledge independently, and even feel disgusted with the learning method of autonomous learning. Based on the above situation, when the knowledge itself is well structured and the difficulty is 
moderate, teachers can give students more space for independent learning. When students encounter difficult knowledge, teachers should provide students with independent learning space while paying attention to the reasonable teaching of knowledge and active guidance, instead of blindly letting students explore independently.

From the overall situation of course implementation, students' mastery of knowledge basically meets expectations. The classroom atmosphere is good during the course teaching. Under the teaching guidance of teachers, students take the initiative to participate and speak actively to realize teacher-student interaction, student-student interaction, and the teaching effect is good. For a long time, the traditional passive teacher-centered teaching mode has hindered students from learning "Web Design and Production", which is not conducive to students' initiative, and it is difficult to increase students' interest in learning, resulting the lack of enthusiasm for active thinking. The student-centered self-learning teaching model has a positive effect on the improvement of this kind of phenomenon. However, in a curriculum that combines practical and theoretical teaching, it is necessary to explore and analyze the specific characteristics of the content suitable for student self-learning and the proportion of content.

\section{References}

1. Zou Y. Category and internal structure of autonomous learning (in Chinese). Social Science Front 2020; (9): 270-275.
2. Wang D. The complementarity and interchangeability of ideas in the network (in Chinese). CEO\&CIO in Information Times 2014; (8): 92.

3. Yuan X. Application of three-card teaching to cultivate students' autonomous learning ability (in Chinese). Education Theory and Practice 2010; (11): 49-50.

4. Castro E, Hyslop B. Basic tutorial for HTML5 and CSS3. $8^{\text {th }}$ ed. Wang Y (translators). Beijing: Posts \& Telecom Press; 2014.

5. Zhu K. Construction significance and strategy of liberal arts laboratory. Modern Education Management 2017; (7): 67-69.

6. Dong Y. Research on teaching mode of college students' autonomous learning with the support of information technology [Master's thesis]. Jinan: Shandong Normal University; 2020.

7. Chen L, Sun J, Ju S, et al. Exploration on application of autonomous learning mode in computer network course. Experimental Technology and Management 2017; 34(252): 186-189.

8. He M, Liu Y. Teaching reform and practice of "Web Design and Making" course based on the mode of "interactive and guidance learning" in colleges. Computer Engineering and Science 2019; 41(S1): 50-54.

9. Luo F. Curriculum reform and practice of web design and production based on project-based teaching (in Chinese). Education and Careers 2014(29): 139140.

10. Ding $\mathrm{H}$. Teaching application and experiment teaching design of webpage design and making. Journal of Yunnan University (Natural Science Edition) 2012; 34(S2): 327-330.

11. Shi B. Task-driven teaching design of web design and production course (in Chinese). Modern Education Science 2010; (S1): 113-114. 